\title{
The philanthropist scholar
}

\author{
John Love, co-author of the famous book Optical Waveguide Theory, passed away on 19 June 2016. \\ The Australian optics community has lost a founding pillar.
}

Following study at Cambridge and Oxford and several years 'postdocing' in San Diego and Toronto, in 1973 John Love was lured by fellowship offers to research optic fibres at the Australian National University (ANU). For the next six years, Allan Snyder and Love worked on the book Optical Waveguide Theory, which remains in print today.

"Unlike me, John had no previous experience with optical waveguide theory, but I saw this as a decided advantage in producing a truly accessible account," Snyder told Nature Photonics. "It all worked brilliantly. To this day, I marvel at how we did it and how it remains a classic text, one that would never have existed without John."

The move for Love to the research topic of optic fibres in 1973 was timely. Adrian Ankiewicz, who was a student at ANU when Love arrived, said that optic fibre analysis was so new at the time that when he told people what he was working on, most had never heard of it, and they thought it must be something in the human eye. He said that while Love authored many papers on optical fibre couplers, planar waveguides, multimode and single-mode fibres, and 'few mode' fibres, he was also a keen student supervisor, facilitated setting up various student prizes, was a major donor to the university and was a supporter of the Cooperative Research Centre for photonics, linking industry with universities in Australia.

Mathematical detail is one of the reasons the optical waveguide book is a trusted reference. Another colleague and friend of Love's, Colin Pask, moved to ANU in 1972. Pask told us that Love was a mathematics expert and was always prepared to read over things for you; there was no way you could 'put one over him. According to Pask, Love was a team player, not a self-promoter, and that the ANU community was his family. Love also had a passion for sports (even if he wasn't good at them) and trains (which led to playful ribbing from colleagues). "He [Love] had travelled on many famous trains and had a great knowledge of railways and their development around the world. He was also a model train enthusiast and had a large display in his basement," Pask explained.

By the 1980s, Love was known as a rather progressive academic. Roderick Boswell told us that when he arrived at ANU in the early 1980s, it was Love who broke the caste of the

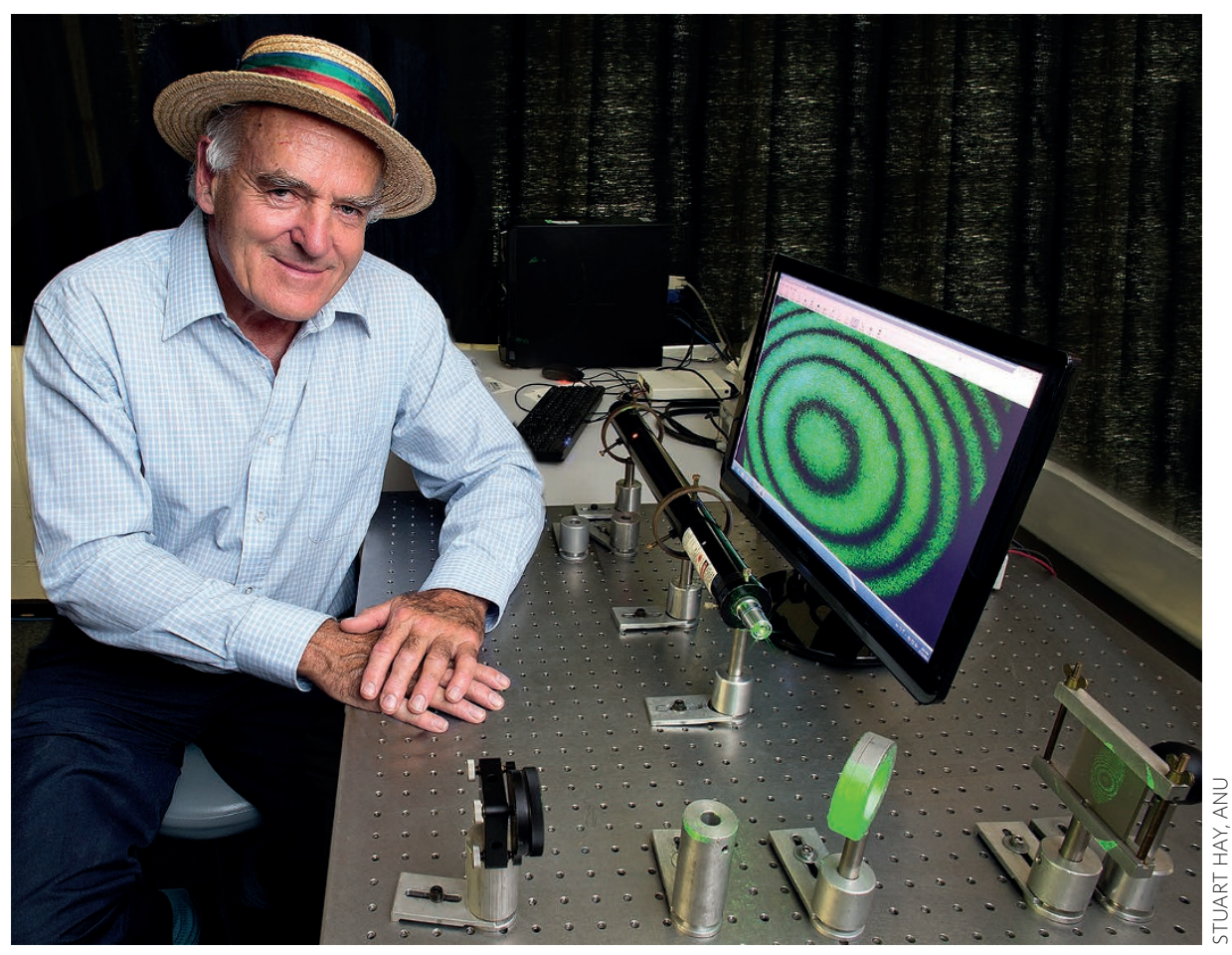

'God' professor. The pair worked in the early 1990s to create plasma-processed optical waveguides from glass with the substrate held at room temperature that would allow eventual integration with III-V devices. "He was an avid, if not downright dangerous, squash player and later spent a considerable amount of his spare time walking up to $50 \mathrm{~km}$ a day," Boswell told Nature Photonics. "He was also a very loyal friend."

In 1989, Love introduced the first undergraduate half-course in fibre optics at ANU that was later expanded into two full courses covering a wider range of light-guiding and optical-communications technologies.

Notably, Love was an early proponent of women in physics. A student of Love's, Wanda Henry, was the first woman to complete a $\mathrm{PhD}$ in photonics at ANU. Sadly, she died at the age of 34; Love was deeply moved, and helped establish the Wanda Henry Scholarship in Photonics in her memory (go.nature.com/2aLyHcb).

Love also had the idea of a scholarship designed to support students who are academically good enough to study at ANU, but for whom it might be particularly financially challenging. In 2014, he established the Love Scholarships with a donation of approximately AUD\$1 million to ANU (go.nature.com/2beXiTq). In an ANU interview, Love said "during the last 40 years I've come across difficult circumstances for friends, relatives, students. It started me thinking about how I could help people, particularly as I don't have any family to support." He said "I'm lucky to be in a position to do that." In 2016, Love "significantly increased his pledge" and made "a generous gift in support of world class cancer research at ANU" (go.nature.com/2aFZ5yC).

Worth watching is an often humorous video filmed in early 2016 (go.nature. $\mathrm{com} / 2 \mathrm{aS} 3 \mathrm{wcW}$ ), not long before his death, in which Love discussed the scholarships and his career. Innovator of the erbium-doped fibre amplifier, David Payne, effectively concludes for us in saying "Love was a great early pioneer of optical fibre theory in the days when these things were poorly understood. John was a mainstay of Australian photonics, a great supporter of $\mathrm{PhD}$ students and very much part of the photonics founding community. He was also a train freak, and I used to beat him at squash!" 